\title{
Protection of oral hydrogen water as an antioxidant on pulmonary hypertension
}

\author{
Bin He $\cdot$ Yufeng Zhang $\cdot$ Bo Kang $\cdot$ \\ Jian Xiao $\cdot$ Bing Xie $\cdot$ Zhinong Wang
}

Received: 26 April 2012/ Accepted: 4 October 2012/Published online: 18 August 2013

(C) The Author(s) 2013. This article is published with open access at Springerlink.com

\begin{abstract}
This study aimed to explore the protective effect of hydrogen as an antioxidant on monocrotaline (MCT)-induced pulmonary hypertension (PH). Forty-eight $\mathrm{SD}$ rats were equally randomized into four groups: SHAM group, MCT group, MCT+Oral- $\mathrm{H}_{2}$ group and MCT+Inj$\mathrm{H}_{2}$ group. The results showed that the mean pulmonary arterial pressure, right ventricle weight and right ventricular hypertrophy index in MCT group were significant higher than those in SHAM group; pulmonary inflammatory response, atrial natriuretic factor, 3-nitrityrosine and intercellular adhesion molecule-1 were also increased significantly in MCT group. These indexes were decreased significantly in both MCT + Oral- $\mathrm{H}_{2}$ group and MCT + Inj$\mathrm{H}_{2}$ group, which indicate Oral- $\mathrm{H}_{2}$ and Inj- $\mathrm{H}_{2}$ have similar effects of preventing the development of $\mathrm{PH}$ and mitigating $\mathrm{RV}$ hypertrophy. The protective effect of hydrogen is associated with its antioxidative ability and action of reducing pulmonary inflammatory response. While Oral- $\mathrm{H}_{2}$
\end{abstract}

Bin He and Yufeng Zhang contributed equally to this work.

\section{B. He ( $\square)$}

Department of Anesthesiology and SICU, Xinhua Hospital, Shanghai Jiaotong University School of Medicine, Kongjiang Road 1665, Shanghai 200092, China

e-mail: 15000330960@139.com

Y. Zhang $\cdot$ B. Kang $\cdot$ J. Xiao $\cdot$ Z. Wang $(\bowtie)$

Department of Cardiothoracic Surgery, Changzheng Hospital,

Second Military Medical University, Fengyang Road 415,

Shanghai 200003, China

e-mail: zyf19810824@163.com

B. Xie

Department of Burn, Changhai Hospital, Second Millitary

Medical University, Changhai Road 168, Shanghai 200433,

China is more convenient than Inj- $\mathrm{H}_{2}$, Oral- $\mathrm{H}_{2}$ may be ideal for clinical use in future.

Keywords Antioxidant · Hydrogen water .

Pulmonary hypertension

\section{Introduction}

Pulmonary hypertension $(\mathrm{PH})$ is clinically characterized by progressive increase of pulmonary arterial pressure and right ventricular hypertrophy [1]. It is believed that $\mathrm{PH}$ is a severe condition attributable to co-action of multiple etiologies and factors, including genetic susceptibility, immunologic disturbances and environmental stimuli [26]. Previous studies mainly focused on the use of vasodilators [7-9], including nitric oxide inhalation, and use of cyclic guanosine monophosphate generating agents, endothelin receptor antagonists and prostatin. However, these vasodilators were unable to radically reverse the progressive increase of PH. It is therefore necessary to find a new strategy that could cure PH effectively and prevent pulmonary vascular resistance from rising progressively [10].

Studies [11-14] have demonstrated that reactive oxygen species (ROS) plays an important role in the occurrence of $\mathrm{PH}$, and those antioxidants are effective in the treatment of $\mathrm{PH}[15,16]$. However, the use of large doses of non-selective antioxidants may induce hemorrhage and other complications [17, 18], and therefore rational use of selective antioxidants is more advantageous in the treatment of PH. Recent studies [19-21] have shown that molecular hydrogen is a selective antioxidant, and plays a role in protecting against ischemia/reperfusion (I/R) injury through selectively clearing hydroxyl radicals $(\mathrm{OH})$ and peroxynitrite (ONOO); and hydrogen does not react with other ROS (e.g., $\mathrm{H}_{2} \mathrm{O}_{2}$ 
and $\mathrm{O}_{2}-$ ), which possess physiological roles. Our previous study [22] also demonstrated that intraperitoneal Inj- $\mathrm{H}_{2}$ could protect against I/R injury through selective anti-oxidization. So we established a PH rat model by intraperitoneal injection of monocrotaline (MCT) to see whether hydrogen was also effective in $\mathrm{PH}$ treatment.

There are various ways [19-22] to administrate molecular hydrogen as a therapeutic antioxidant, inhalation of hydrogen gas, oral administration of hydrogen water, intraperitoneal or intravenous injection of hydrogen-rich saline. As hydrogen gas is explosive, this might be potential dangerous for clinical application. Besides using Inj- $\mathrm{H}_{2}$ in our previous study [22], we also made new modification in production and administration of hydrogen by using Oral- $\mathrm{H}_{2}$ in the present study. And we will also compare these two different ways to administrate hydrogen in therapeutic effect on MCT-induced PH.

\section{Materials and methods}

Animals

Adult SD rats weighing 250-280 g (Experimental Animal Center of the Second Military Medical University, Shanghai, China) were housed with free access to food and water under a natural day/night cycle, and acclimated for 7 days before any experimental procedure. All experimental procedures were approved by the Institutional Animal Care and Use Committee of the Second Military Medical University in Shanghai, China.

Production of Oral- $\mathrm{H}_{2}$ and $\mathrm{Inj}-\mathrm{H}_{2}$

Oral- $\mathrm{H}_{2}$ [20]: The magnesium stick used to produce hydrogen in the study was a plastic-shelled product consisting of metallic magnesium (99.9\% pure) and natural stones in a polypropylene container combined with ceramics (Doctor SUISOSUI ${ }^{\circledR}$, Friendear, Tokyo, Japan). It was able to generate hydrogen when placed in drinking water through the following chemical reaction: $\mathrm{Mg}+2 \mathrm{H}_{2} \mathrm{O} \rightarrow \mathrm{M}$ $\mathrm{g}(\mathrm{OH})_{2}+\mathrm{H}_{2}$. The hydrogen concentration in the water bottle was sequentially monitored using a hydrogen needle sensor (DHS-001, ABLE, Tokyo, Japan) and maintained at a level between 0.55 and $0.65 \mathrm{mmol}$ and $\mathrm{pH} 7.7-8.3$.

Inj- $\mathrm{H}_{2}$ [22]: Hydrogen was dissolved in $0.9 \%$ saline for $6 \mathrm{~h}$ under a high pressure $(0.4 \mathrm{MPa})$ to a supersaturated level. Hydrogen saline was stored under an atmospheric pressure at $4{ }^{\circ} \mathrm{C}$ in an aluminum bag with no dead volume, sterilized by gamma radiation, and freshly prepared once a week to ensure that the concentration was maintained at $0.6 \mathrm{mmol} / \mathrm{L}$. Gas chromatography was performed to confirm the content of hydrogen in saline.
Establishment of the in vivo rat model and experimental protocols

Forty-eight SD rats were equally randomized to four groups: SHAM group as the control, MCT group, $\mathrm{MCT}+\mathrm{Oral}-\mathrm{H}_{2}$ group and $\mathrm{MCT}+\mathrm{Inj}-\mathrm{H}_{2}$ group. Animals in SHAM group were administered with Oral- $\mathrm{H}_{2}$ only, and the other groups were administered with intraperitoneal injection of MCT $(80 \mathrm{mg} / \mathrm{kg})$.

Fourteen days later, the mean pulmonary arterial pressure (mPAP) was measured in all the groups. Animals in MCT group were administered with ordinary drinking water thereafter. Those in $\mathrm{MCT}+\mathrm{Oral}-\mathrm{H}_{2}$ group or $\mathrm{MCT}+\mathrm{Inj}-\mathrm{H}_{2}$ group were administered with $\mathrm{Oral}-\mathrm{H}_{2}$ or Inj- $\mathrm{H}_{2}$ respectively.

Additional 14 days later, mPAP was measured again. All animals were then sacrificed, and the heart and lung tissue were removed for morphologic observation and related tests.

\section{Determination of mPAP}

The rats were anesthetized by intraperitoneal injection of $300 \mathrm{mg} / \mathrm{kg}$ chloral hydrate and fixed in a supine position. The right jugular vein was isolated, through which a PE50 catheter was inserted to the right ventricle (RV) to the right atrium, and finally placed in the pulmonary trunk. The end of the catheter was connected to a pressure sensor to monitor, analyze and record mPAP in a real-time manner.

\section{Measurement of RVHI}

The RV, left ventricle (LV) and septum (S) were weighed separately. The right ventricular hypertrophy index (RVHI) was measured by $\mathrm{RV} /(\mathrm{LV}+\mathrm{S})$ weight.

\section{Histopathology of lung injury and RV hypertrophy}

Lung injury [23] The pulmonary tissues were stained with HE. Morphological lung injury in different groups was assessed by at least two pathologists independently according to the procedures described previously.

Determination of ANF Besides RVHI, ANF is another marker for RV hypertrophy. Blood for plasma atrial natriuretic factor (ANF) measurements were collected in heparinized syringes. Plasma was separated by centrifugation and frozen at $-70{ }^{\circ} \mathrm{C}$. Plasma ANF was measured by ELISA method (Abcam Inc.) [24].

Determination of 3-nt and ICAM-1 levels

Immunohistochemistry The rats were sacrificed, and the lung tissue was sliced, fixed, paraffin-embedded and 
dewaxed routinely as described [22]. The primary antibodies for the determination of 3-nitrityrosine (3-nt) and intercellular adhesion molecule-1 (ICAM-1) were products of Abcam Inc., and the secondary antibodies were products of R\&D Systems. The prepared immunohistochemical sections were observed in randomly selected four fields $(\times 20)$, and the number of 3-nt and ICAM-1 positive cells was counted quantitatively.

Western blot The protein expression of 3-nt and ICAM1 was detected similar to our previous study [25]. All the same membranes were probed with $\beta$-actin as loading controls.

\section{Statistical analysis}

Quantitative data were expressed as mean \pm SD. Differences within the three groups were determined with oneway ANOVA and Student-Newman-Keuls test. $P<0.05$ was considered statistically significant.

\section{Results}

MPAP and RVHI measurement

Fourteen days after intraperitoneal injection of MCT, mPAP in MCT, MCT + Oral- $\mathrm{H}_{2}$ and $\mathrm{MCT}+\mathrm{Inj}-\mathrm{H}_{2}$ groups was $29.6 \pm 7.2 \mathrm{mmHg}, \quad 28.4 \pm 8.5 \mathrm{mmHg}$ and $29.1 \pm 8.7 \mathrm{mmHg}$ respectively. They were all significantly higher than that in SHAM group which was $18.6 \pm 4.3 \mathrm{mmHg} \quad(P<0.05), \quad$ indicating successful establishment of PH animal model. There was no significant difference in mPAP within MCT group, MCT+Oral$\mathrm{H}_{2}$ group and $\mathrm{MCT}+\mathrm{Inj}-\mathrm{H}_{2}$ group $(P>0.05)$.

After additional 14 days, mPAP and RVHI were measured again. As shown in Table 1, mPAP, RV and RVHI in MCT group were all significantly higher than those in SHAM group $(P<0.05)$. While these indexes were decreased significantly in $\mathrm{MCT}+\mathrm{Oral}-\mathrm{H}_{2}$ group and $\mathrm{MCT}+\mathrm{Inj}-\mathrm{H}_{2}$ group $(P<0.05)$, indicating that both Oral-
$\mathrm{H}_{2}$ and Inj- $\mathrm{H}_{2}$ can alleviate MCT-induced $\mathrm{PH}$. There was no significant difference between $\mathrm{MCT}+\mathrm{Oral}-\mathrm{H}_{2}$ group and $\mathrm{MCT}+\mathrm{Inj}-\mathrm{H}_{2}$ group $(P>0.05)$, which indicate Oral$\mathrm{H}_{2}$ and Inj- $\mathrm{H}_{2}$ have similar protective effect on $\mathrm{PH}$.

\section{Assessment of RV hypertrophy}

PH can induce RV hypertrophy. Besides RVHI, ANF is another marker for RV hypertrophy. Plasma ANF was detected by ELISA method. The results showed that ANF in MCT group was significantly higher than that in SHAM group $(P<0.05)$. While ANF was decreased significantly in $\mathrm{MCT}+\mathrm{Oral}-\mathrm{H}_{2}$ group and $\mathrm{MCT}+\mathrm{Inj}-\mathrm{H}_{2}$ group than in MCT group $(P<0.05)$ (Table 1$)$.

Determination of 3-nt

Immunohistochemistry for 3-nt was performed on biopsies obtained from the lungs. The number of 3-nt positive cells in MCT group were significantly greater than that in SHAM group, with a positive rate of $66 \pm 11 \%$ $(P<0.05)$, indicating that nitrative stress in MCT group was increased. While the number of 3-nt positive cells in $\mathrm{MCT}+\mathrm{Oral}-\mathrm{H}_{2}$ group and $\mathrm{MCT}+\mathrm{Inj}-\mathrm{H}_{2}$ group were significantly lower than that in $\mathrm{MCT}$ group, with a positive rate of $42 \pm 8 \%$ and $44 \pm 7 \%$ respectively $(P<0.05)$, indicating that both Oral- $\mathrm{H}_{2}$ and $\mathrm{Inj}-\mathrm{H}_{2}$ can mitigate the nitrative stress in the course of PH formation (Fig. 1a, b).

The protein expression of 3-nt in different groups was determined by western blot. The protein expression of 3-nt in MCT group was up-regulated than that in SHAM group, while both Oral- $\mathrm{H}_{2}$ and $\mathrm{Inj}-\mathrm{H}_{2}$ can down-regulate the expression of 3-nt (Fig. 1c).

\section{Determination of ICAM-1}

Immunohistochemistry for ICAM-1 was performed. The number of ICAM-1 positive cells in MCT group were significantly greater than that in SHAM group, with a positive rate of $28 \pm 5 \% \quad(P<0.05)$, implying that

Table 1 General results obtained at day 28

\begin{tabular}{|c|c|c|c|c|}
\hline & SHAM group & MCT group & $\mathrm{MCT}+$ Oral- $\mathrm{H}_{2}$ group & $\mathrm{MCT}+$ Inj- $\mathrm{H}_{2}$ group \\
\hline Body weight (g) & $321 \pm 8.6$ & $275 \pm 11.6^{*}$ & $281 \pm 13.8^{*}$ & $288 \pm 13.4^{*}$ \\
\hline Heart weight (g) & $0.93 \pm 0.042$ & $1.17 \pm 0.073^{*}$ & $1.11 \pm 0.061 *$ & $1.13 \pm 0.065^{*}$ \\
\hline RV weight (g) & $0.18 \pm 0.004$ & $0.438 \pm 0.051 *$ & $0.346 \pm 0.041 *^{*}$ & $0.349 \pm 0.040^{* *}$ \\
\hline $\mathrm{LV}+\mathrm{S}$ weight $(\mathrm{g})$ & $0.751 \pm 0.031$ & $0.734 \pm 0.021$ & $0.755 \pm 0.032$ & $0.745 \pm 0.028$ \\
\hline RVHI & $0.24 \pm 0.014$ & $0.59 \pm 0.065^{*}$ & $0.45 \pm 0.048^{* *}$ & $0.47 \pm 0.052^{* *}$ \\
\hline mPAP $(\mathrm{mmHg})$ & $19.8 \pm 5.1$ & $44.6 \pm 7.2^{*}$ & $31.4 \pm 6.5^{* *}$ & $32.2 \pm 6.7^{* *}$ \\
\hline Plasma ANF (pg/ml) & $185.6 \pm 53.8$ & $693.7 \pm 165.9^{*}$ & $407.2 \pm 102.3^{* *}$ & $423.4 \pm 114.0^{*^{*}}$ \\
\hline
\end{tabular}

$* P<0.05$ compared with SHAM group; ${ }^{*} P<0.05$ compared with MCT group 
Fig. 1 3-nt levels in different groups.

a Immunohistochemistry. The inset in the lower right corner of the figure showed a section at larger scales, and arrows to show the positive cells.

b Positive rate. The number of 3-nt positive cells in MCT group was significantly greater than that in SHAM group, and the number of 3-nt positive cells in $\mathrm{MCT}+\mathrm{Oral}-\mathrm{H}_{2}$ and $\mathrm{MCT}+\mathrm{Inj}-\mathrm{H}_{2}$ groups was significantly lower than that in MCT group. c Western blot. The protein expression of 3-nt in MCT group was up-regulated than that in SHAM group, while both Oral- $\mathrm{H}_{2}$ and Inj- $\mathrm{H}_{2}$ can down-regulate the expression of 3-nt. $(* P<0.05$ compared with SHAM group; ${ }^{*} P<0.05$ compared with MCT group)
A
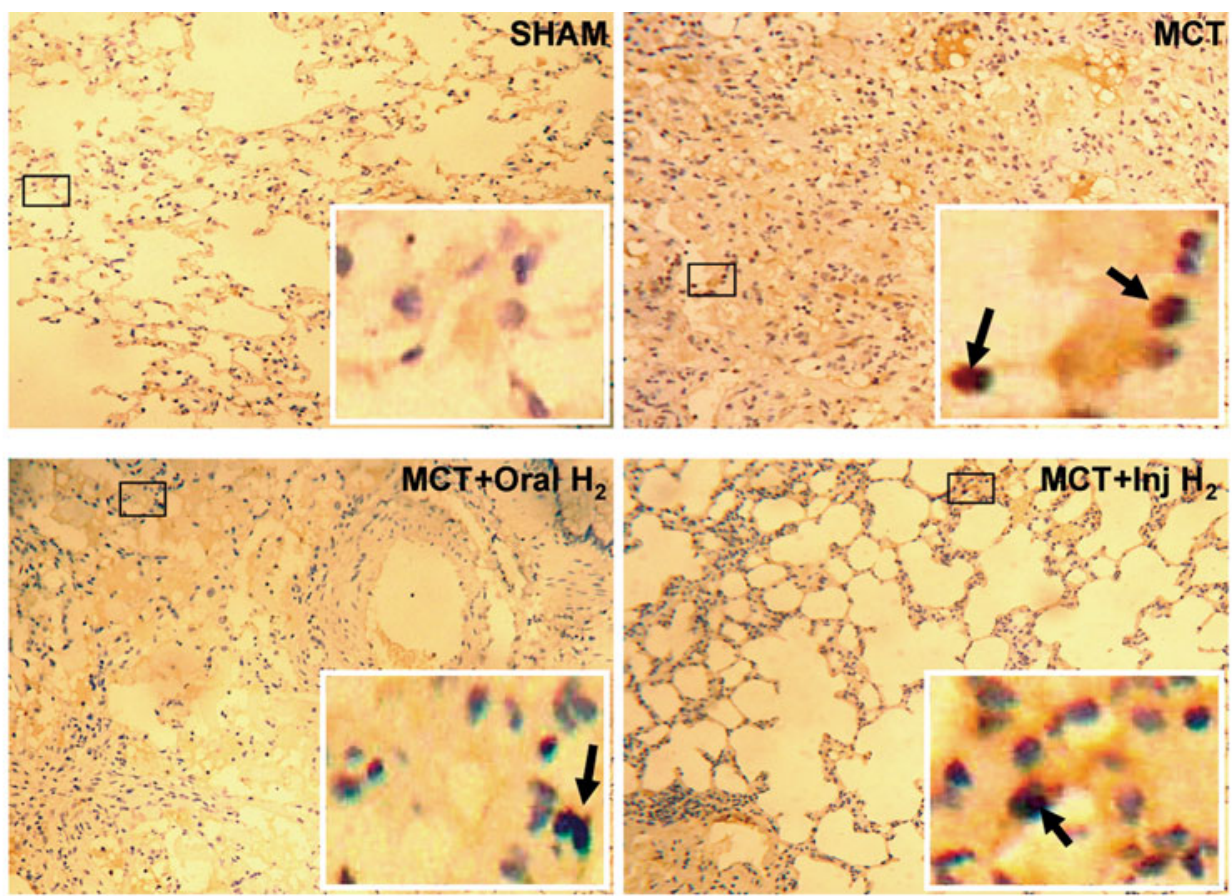

B

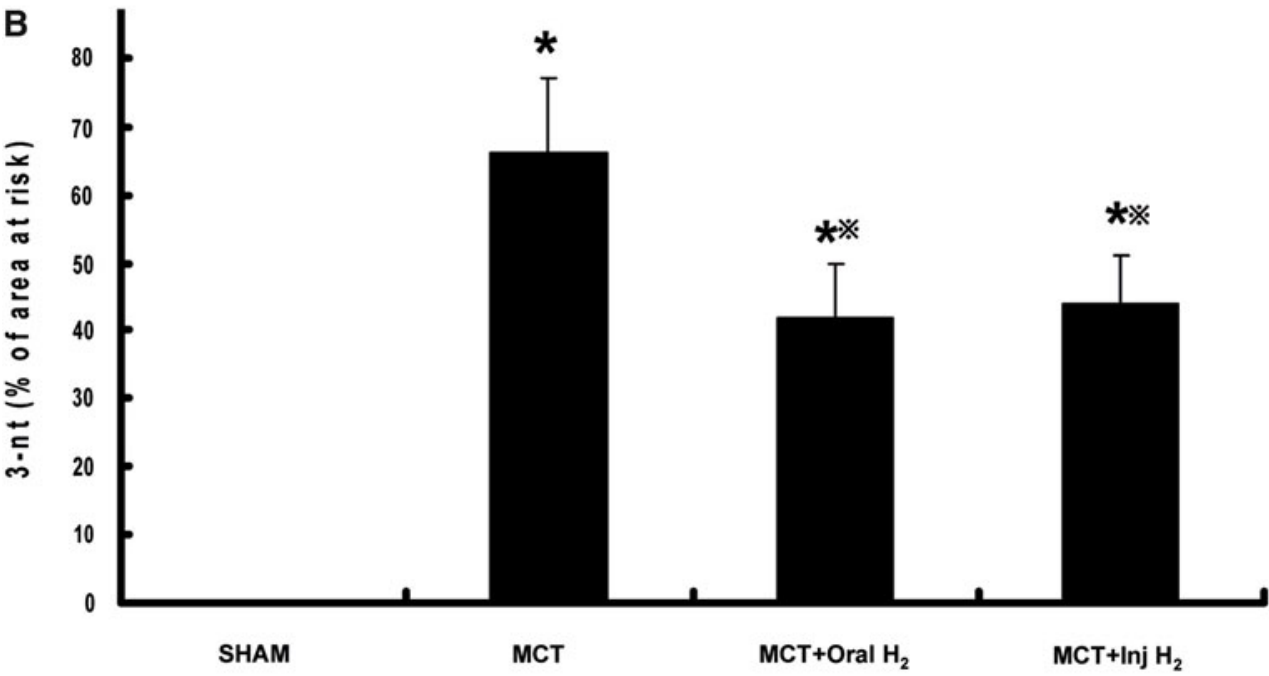

C

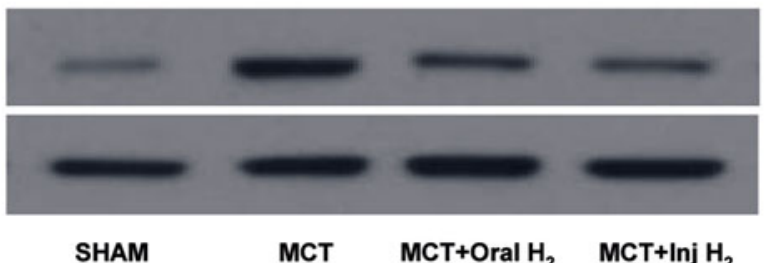

3-nt

B -Actin
ICAM-1 infiltration was increased in MCT group. The number of ICAM-1 positive cells in MCT + Oral- $\mathrm{H}_{2}$ group and $\mathrm{MCT}+\mathrm{Inj}-\mathrm{H}_{2}$ group were significantly lower than that in MCT group, with a positive rate of $13 \pm 3 \%$ and $12 \pm 3 \%$ respectively $(P<0.05)$, suggesting that both
Oral- $\mathrm{H}_{2}$ and Inj- $\mathrm{H}_{2}$ can mitigate ICAM-1 infiltration in the course of PH formation (Fig. 2a, b).

The protein expression of ICAM-1 in different groups was determined by Western blot. The protein expression of ICAM-1 in MCT group was up-regulated than that in 
Fig. 2 ICAM-1 levels in different groups.

a Immunohistochemistry. The inset in the lower right corner of the figure showed a section at larger scales, and arrows to show the positive cells.

b Positive rate. The number of ICAM-1 positive cells in MCT group was significantly greater than that in SHAM group, and the number of ICAM-1 positive cells in MCT + Oral- $\mathrm{H}_{2}$ and $\mathrm{MCT}+\mathrm{Inj}-\mathrm{H}_{2}$ groups was significantly smaller than that in MCT group. c Western blot. The protein expression of ICAM-1 in MCT group was upregulated than that in SHAM group, while both Oral- $\mathrm{H}_{2}$ and Inj- $\mathrm{H}_{2}$ can down-regulate the expression of ICAM-1. ${ }^{*} P<0.05$ compared with SHAM group; ${ }^{*} P<0.05$ compared with MCT group)
A
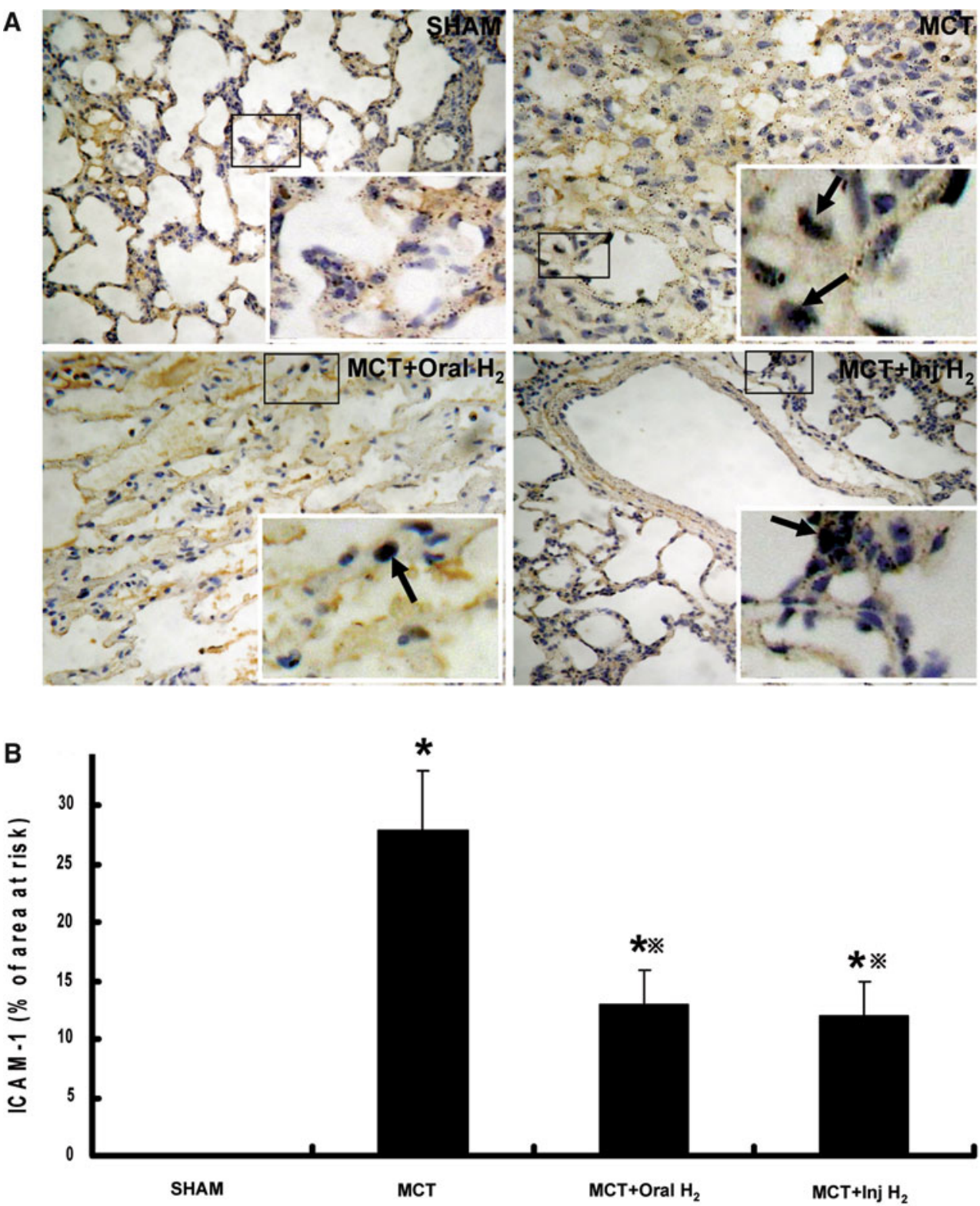

C

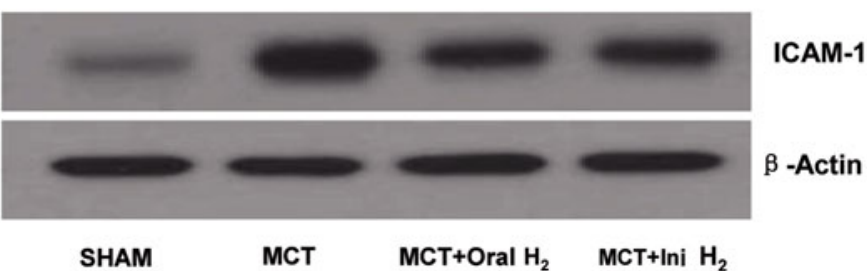

SHAM group, while both Oral- $\mathrm{H}_{2}$ and $\mathrm{Inj}-\mathrm{H}_{2}$ can downregulate the expression of ICAM-1 (Fig. 2c).

Analysis and scoring of lung tissue injury

There was no significantly abnormal change in lung tissue was observed in SHAM group, while there was significant evidence of inflammatory response in the lung tissue of the rats in MCT group, presenting as fracture of parenchymal cells, infiltration of macrophages and chronic inflammatory cells, and significant thickening of alveolar septa and cavities. Compared with MCT group, these inflammatory responses were significantly ameliorated in both $\mathrm{MCT}+\mathrm{Oral}-\mathrm{H}_{2}$ group and $\mathrm{MCT}+\mathrm{Inj}-\mathrm{H}_{2}$ group (Fig. $3 \mathrm{a}$ ). The tissue injury score was $11 \pm 5$ in SHAM group, $25 \pm 7$ in MCT group, $18 \pm 6$ in $\mathrm{MCT}+\mathrm{Oral}-\mathrm{H}_{2}$ group 
and $17 \pm 5$ in $\mathrm{MCT}+$ Inj- $\mathrm{H}_{2}$ group, which indicated that tissue injury in MCT group was more severe than that in SHAM group $(P<0.05)$, while that in $\mathrm{MCT}+\mathrm{Oral}-\mathrm{H}_{2}$ group and $\mathrm{MCT}+\mathrm{Inj}-\mathrm{H}_{2}$ group was ameliorated significantly $(P<0.05)$ (Fig. 3b).

\section{Discussion}

Inflammatory response in lung tissue, progressive increase of pulmonary arterial pressure and pulmonary vascular resistance, resultant RV hypertrophy and remodeling are typical pathological presentations of PH [26]. RVHI and plasma ANF were detected, both of which are markers for
RV hypertrophy. Both RVHI and ANF were decreased significantly by hydrogen. These results of the present study showed that hydrogen can relieve MCT-induced PH markedly and reverse RV hypertrophy. It was found in our experiment that hydrogen was able to reduce the thickness of alveolar septa and the number of chronic inflammatory cells in the course of $\mathrm{PH}$ formation, thus mitigating RV hypertrophy. Knowing that ROS is closely correlated with RV hypertrophy as demonstrated in previous studies [27], and that hydrogen can clear ROS, we suppose that the mechanism of hydrogen in mitigating RV hypertrophy is via selectively clearing ROS and reducing pulmonary arterial pressure. As a result, not only RV load was reduced but RV hypertrophy was mitigated.
Fig. 3 Results of lung tissue injury. a HE Staining. In SHAM group, the lung tissue was normal. In MCT group, inflammatory injury to the lung tissue was severe, presenting as fracture of the alveolar septa and infiltration of macrophages and chronic inflammatory cells as indicated by the presence of scattered red blood cells. Media thickening, luminal narrowing, fibroblast proliferation and adventitial inflammatory response in pulmonary arterioles. In the lung tissue sections of MCT + Oral- $\mathrm{H}_{2}$ and $\mathrm{MCT}+\mathrm{Inj}-\mathrm{H}_{2}$ groups, the number of inflammatory cells was reduced significantly, and alveolar septa were also reduced significantly as compared with SHAM group. b Lung injury score. Semi-quantitative scoring of the lung tissue in different groups showed that the lung tissue injury score of MCT group was significantly higher than that of SHAM group, and the lung tissue injury score of $\mathrm{MCT}+\mathrm{Oral}-\mathrm{H}_{2}$ and MCT+Inj$\mathrm{H}_{2}$ groups was significantly lower than that of MCT group ( $* P<0.05$ compared with SHAM group; ${ }^{*} P<0.05$ compared with MCT group)

\section{A}
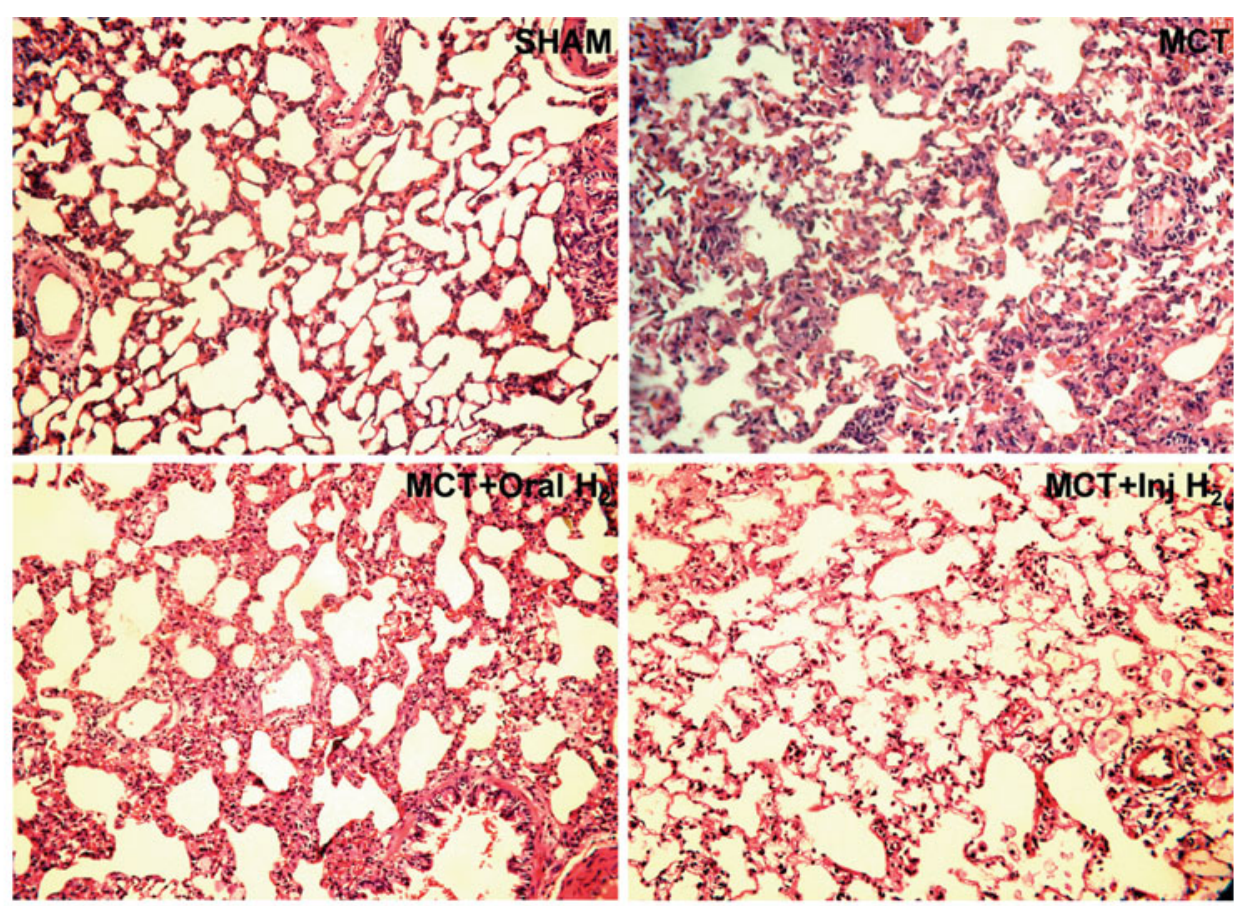

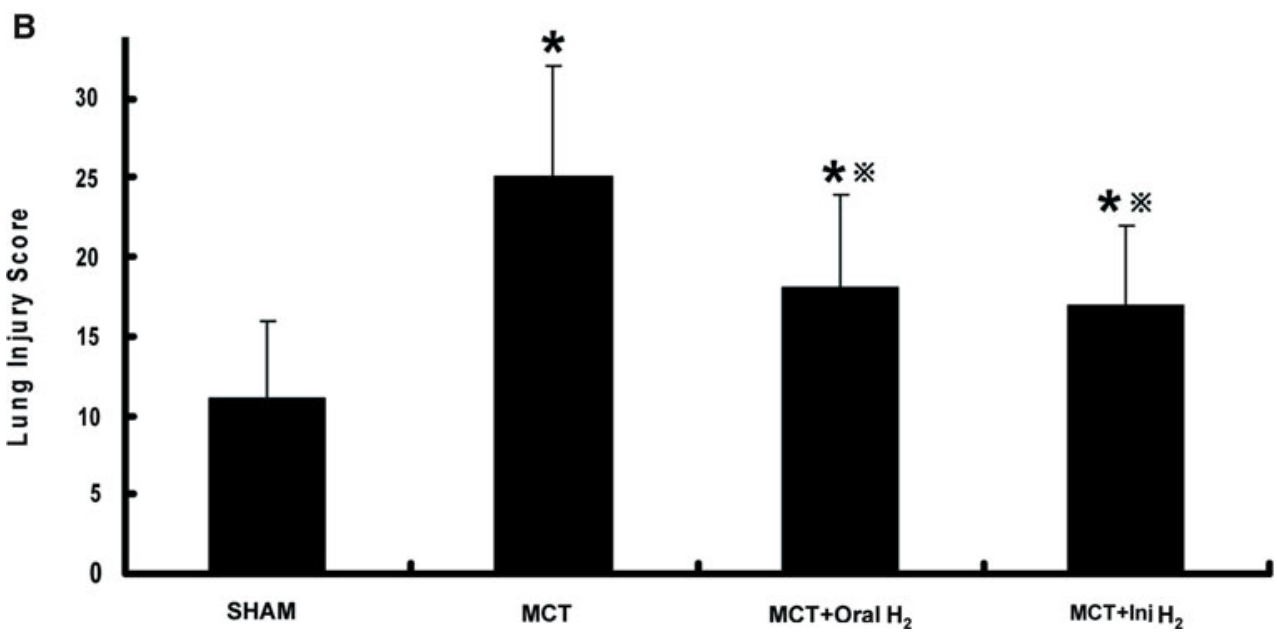


Table 2 Comparison between two different ways to administrate hydrogen

\begin{tabular}{|c|c|c|}
\hline & Oral- $\mathrm{H}_{2}$ & Inj- $\mathrm{H}_{2}$ \\
\hline Administration \& absorption & $\begin{array}{l}\text { Oral administration is non-invasive; gastrointestinal } \\
\text { tract absorption is physiological }\end{array}$ & $\begin{array}{l}\text { Injection is invasive; intraperitoneal or intravenous } \\
\text { absorption is non-physiological }\end{array}$ \\
\hline Production \& storage & Convenient; normal pressure; normal temperature & $\begin{array}{l}\text { Need more higher pressure to produce; storage at } \\
4{ }^{\circ} \mathrm{C} \text {; need special instrument to store: aluminum } \\
\text { bag without dead volume }\end{array}$ \\
\hline Release time & $\begin{array}{l}\text { Continuous; release hydrogen as long as magnesium } \\
\text { stick not depleted }\end{array}$ & $\begin{array}{l}\text { Transient; need freshly preparation every week to } \\
\text { ensure a constant concentration of greater than } \\
0.6 \mathrm{mM}\end{array}$ \\
\hline Cost & Less; only $10-15 \%$ price of $\mathrm{Inj}-\mathrm{H}_{2}$ & More \\
\hline Clinical application & $\begin{array}{l}\text { Ideal and convenient for patients without changing } \\
\text { their lifestyle }\end{array}$ & Need injection everyday \\
\hline
\end{tabular}

Previous studies have demonstrated that chronic inflammatory response plays an crucial role in the development and progression of PH [2], and that increased ROS production is inextricably associated with chronic inflammatory response [28], which is also confirmed by the fact that antioxidants are effective in the treatment of $\mathrm{PH}[15$, 23]. Our previous experiment [22] demonstrated that molecular hydrogen had an anti-inflammatory effect on I/R injury. The present study further confirmed that molecular hydrogen was able to mitigate the infiltration of inflammatory cells in the course of MCT-induced PH formation, thus relieving inflammatory response. ICAM-1 is one of the main adhesion molecules mediating neutrophil adhesion, and is regulated by such cytokines as TNF- $\alpha$ and IL1b. After cytokine regulation, ICAM-1 is up-regulated rapidly, thus progressively aggravating the inflammatory response. If ICAM-1 could be reduced effectively, inflammatory response in the course of pathological injury would be mitigated [29, 30]. It was found in the present study that hydrogen could reduce ICAM-1 level in the course of $\mathrm{PH}$ formation and infiltration of chronic inflammatory cells in local lung tissue, thus relieving the severity of $\mathrm{PH}$.

It was also found in our study that improvement of $\mathrm{PH}$ was significantly correlated with 3-nt level. 3-nt is a specific metabolic product of ONOO-, reflecting the level of nitrative stress in vivo [31]. The fact that hydrogen could effectively relieve MCT-induced PH implies that ONOOplays an important role in the development and progression of PH. There are various types of ROS produced in vivo, including hydroxyl free radical, ONOO-, peroxide and superoxide anion. But which ROS actually plays a role in the development and progression of $\mathrm{PH}$ remains unclear. Previous related studies mainly focused on the use of antioxidants, and few studies have focused on which ROS or how many ROS playing the role. The present study demonstrated that hydrogen could reduce 3-nt level markedly and mitigate the pathological process of $\mathrm{PH}$, which indirectly proves that $\mathrm{ONOO}$ - may participate in $\mathrm{PH}$ formation. It is noteworthy that some studies [32] also found that ONOO- played an important role in chronic inflammation, which may explain why reducing ONOOlevel could mitigate the severity of $\mathrm{PH}$.

Although studies showed that some antioxidants could effectively reduce $\mathrm{PH}$, few of them have been used clinically. Imbalance in the endogenous redox state due to nonselective clearance is supposed to be the main reason for failure of some antioxidants in the treatment of $\mathrm{PH}[33$, 34]. Selective clearance is therefore the rational method for effective treatment of PH. It has been proved [19] that molecular hydrogen is a selective antioxidant, which can selectively clear $\mathrm{OH}$ and ONOO-. And hydrogen does not react with other ROS, which possess physiological roles. In addition, due to the small molecular weight, hydrogen can easily enter cell membrane and organelle membrane. These are the advantages of hydrogen in playing antioxidative effect on $\mathrm{PH}$.

In our previous study [22], we used intraperitoneal Inj$\mathrm{H}_{2}$ as an antioxidant. In the present study, we made new modification in production and administration of hydrogen by using oral hydrogen water $\left(\mathrm{Oral}-\mathrm{H}_{2}\right)$ generated by magnesium stick. The results showed Oral- $\mathrm{H}_{2}$ and $\mathrm{Inj}-\mathrm{H}_{2}$ have similar effect of preventing the development of $\mathrm{PH}$ and mitigating RV hypertrophy.

As shown in Table 2, we also compared between the two different ways to administrate hydrogen $\left(\mathrm{Oral}-\mathrm{H}_{2}\right.$ and Inj- $\mathrm{H}_{2}$ ). Unlike Inj- $\mathrm{H}_{2}$, The administration and absorption of Oral- $\mathrm{H}_{2}$ are non-invasive and physiological. As hydrogen can also be produced in the human intestinal tract, it is safe to drink a certain amount of Oral- $\mathrm{H}_{2}$. Inj- $\mathrm{H}_{2}$ needs high pressure $(0.4 \mathrm{MPa})$ to produce, and is stored under atmospheric pressure at $4{ }^{\circ} \mathrm{C}$ in an aluminum bag without dead volume. While the production and storage of Oral- $\mathrm{H}_{2}$ are more convenient, just under normal pressure and normal temperature. The release time of $\mathrm{Inj}-\mathrm{H}_{2}$ is transient, need freshly preparation every week to ensure a constant 
concentration of greater than $0.6 \mathrm{mM}$. While Oral- $\mathrm{H}_{2}$ can release hydrogen continuously as long as magnesium stick not depleted. And the cost of Oral- $\mathrm{H}_{2}$ is only $10-15 \%$ price of Inj- $\mathrm{H}_{2}$. Oral- $\mathrm{H}_{2}$ is more convenient, less costly and longer release time than Inj- $\mathrm{H}_{2}$, and drinking water containing a high concentration of hydrogen is a novel, safe and potent approach for the prevention and treatment of $\mathrm{PH}$, so Oral- $\mathrm{H}_{2}$ may be more ideal for patients in future, as it can be administered without changing their lifestyle.

In summary, the results of the present experiment showed that hydrogen can reduce $\mathrm{PH}$, mitigate $\mathrm{RV}$ hypertrophy by reduce RVHI and ANF in a MCT-induced $\mathrm{PH}$ rat model. In addition, hydrogen could reduce inflammatory response and 3-nt and ICAM-1 levels in the course of $\mathrm{PH}$ formation, suggesting that the therapeutic effect of hydrogen in the treatment of $\mathrm{PH}$ is closely correlated with antioxidative stress. While Oral- $\mathrm{H}_{2}$ is more convenient than Inj- $\mathrm{H}_{2}$, so Oral- $\mathrm{H}_{2}$ may be more ideal for clinical use in future. Next step, we plan to make in-depth study on the mechanism of hydrogen in reducing $\mathrm{PH}$, especially the influence of hydrogen on cytokines that are closely associated with $\mathrm{PH}$.

Acknowledgments This work was supported by the National Nature Science Foundation of China (No. 81270003, 81100826, 30901470), Research Fund for Outstanding Young Teachers in Shanghai Colleges (shjdy1048), Youth Fund of Shanghai Jiao Tong University School of Medicine (11XJ21021) and B Braun Anesthesia Scientific Research Fund (BB-2011-013).

Open Access This article is distributed under the terms of the Creative Commons Attribution License which permits any use, distribution, and reproduction in any medium, provided the original author(s) and the source are credited.

\section{References}

1. Rich S, Chomka E, Hasara L, Hart K, Drizd T, Joo E, Levy PS (1989) The prevalence of pulmonary hypertension in the United States. Adult population estimates obtained from measurements of chest roentgenograms from the NHANES II Survey. Chest 96:236-241

2. Hassoun PM, Mouthon L, Barberà JA, Eddahibi S, Flores SC, Grimminger F, Jones PL, Maitland ML, Michelakis ED, Morrell NW, Newman JH, Rabinovitch M, Schermuly R, Stenmark KR, Voelkel NF, Yuan JX, Humbert M (2009) Inflammation, growth factors, and pulmonary vascular remodeling. J Am Coll Cardiol 54:S10-S19

3. Morrell NW, Adnot S, Archer SL, Dupuis J, Jones PL, MacLean MR, McMurtry IF, Stenmark KR, Thistlethwaite PA, Weissmann N, Yuan JX, Weir EK (2009) Cellular and molecular basis of pulmonary arterial hypertension. J Am Coll Cardiol 54:S20-S31

4. Chan SY, Loscalzo J (2008) Pathogenic mechanisms of pulmonary arterial hypertension. J Mol Cell Cardiol 44:14-30

5. Machado RD, Eickelberg O, Elliott CG, Geraci MW, Hanaoka M, Loyd JE, Newman JH, Phillips JA 3rd, Soubrier F, Trembath
RC, Chung WK (2009) Genetics and genomics of pulmonary arterial hypertension. J Am Coll Cardiol 54:S32-S42

6. Lai YL, Law TC (2004) Chronic hypoxia- and monocrotalineinduced elevation of hypoxia-inducible factor-1 alpha levels and pulmonary hypertension. J Biomed Sci 11:315-321

7. Chen YF, Jowett S, Barton P, Malottki K, Hyde C, Gibbs JS, Pepke-Zaba J, Fry-Smith A, Roberts J, Moore D (2009) Clinical and cost-effectiveness of epoprostenol, iloprost, bosentan, sitaxentan and sildenafil for pulmonary arterial hypertension within their licensed indications: a systematic review and economic evaluation. Health Technol Assess 13:1-320

8. Beghetti M (2006) Current treatment options in children with pulmonary arterial hypertension and experiences with oral bosentan. Eur J Clin Invest 36:16-24

9. Ghofrani HA, Barst RJ, Benza RL, Champion HC, Fagan KA, Grimminger F, Humbert M, Simonneau G, Stewart DJ, Ventura C, Rubin LJ (2009) Future perspectives for the treatment of pulmonary arterial hypertension. J Am Coll Cardiol 54:S108S117

10. Firth AL, Yuan JX (2008) Bringing down the ROS: a new therapeutic approach for PPHN. Am J Physiol Lung Cell Mol Physiol 295:L976-L978

11. Fresquet F, Pourageaud F, Leblais V, Brandes RP, Savineau JP, Marthan R, Muller B (2006) Role of reactive oxygen species and gp91phox in endothelial dysfunction of pulmonary arteries induced by chronic hypoxia. Br J Pharmacol 148:714-723

12. Aziz SM, Toborek M, Hennig B, Mattson MP, Guo H, Lipke DW (1997) Oxidative stress mediates monocrotaline-induced alterations in tenascin expression in pulmonary artery endothelial cells. Int J Biochem Cell Biol 29:775-787

13. Gong Y, Yi M, Fediuk J, Lizotte PP, Dakshinamurti S (2010) Hypoxic neonatal pulmonary arterial myocytes are sensitized to ROS-generated 8-isoprostane. Free Radic Biol Med 48:882-894

14. Afanaśev I (2011) ROS and RNS signaling in heart disorders: could antioxidant treatment be successful. Oxid Med Cell Longev 2011:293769

15. Zhang TT, Cui B, Dai DZ, Tang XY (2005) Pharmacological efficacy of CPU 86017 on hypoxic pulmonary hypertension in rats: mediated by direct inhibition of calcium channels and antioxidant action, but indirect effects on the ET-1 pathway. J Cardiovasc Pharmacol 46:727-734

16. Csiszar A, Labinskyy N, Olson S, Pinto JT, Gupte S, Wu JM, Hu F, Ballabh P, Podlutsky A, Losonczy G, de Cabo R, Mathew R, Wolin MS, Ungvari Z (2009) Resveratrol prevents monocrotaline-induced pulmonary hypertension in rats. Hypertension 54:668-675

17. Sauer H, Wartenberg M, Hescheler J (2001) Reactive oxygen species as intracellular messengers during cell growth and differentiation. Cell Physiol Biochem 11:173-186

18. Liu H, Colavitti R, Rovira II, Finkel T (2005) Redox-dependent transcriptional regulation. Circ Res 97:967-974

19. Ohsawa I, Ishikawa M, Takahashi K, Watanabe M, Nishimaki K, Yamagata K, Katsura K, Katayama Y, Asoh S, Ohta S (2007) Hydrogen acts as a therapeutic antioxidant by selectively reducing cytotoxic oxygen radicals. Nat Med 13:688-694

20. Gu Y, Huang CS, Inoue T, Yamashita T, Ishida T, Kang KM, Nakao A (2010) Drinking hydrogen water ameliorated cognitive impairment in senescence-accelerated mice. J Clin Biochem Nutr 46:269-276

21. Mao YF, Zheng XF, Cai JM, You XM, Deng XM, Zhang JH, Jiang L, Sun XJ (2009) Hydrogen-rich saline reduces lung injury induced by intestinal ischemia/reperfusion in rats. Biochem Biophys Res Commun 381:602-605

22. Zhang Y, Sun Q, He B, Xiao J, Wang Z, Sun X (2011) Antiinflammatory effect of hydrogen-rich saline in a rat model of 
regional myocardial ischemia and reperfusion. Int $\mathrm{J}$ Cardiol 148:91-95

23. Baybutt RC, Molteni A (1999) Dietary beta-carotene protects lung and liver parenchyma of rats treated with monocrotaline. Toxicology 137:69-80

24. Klinger JR, Petit RD, Curtin LA, Warburton RR, Wrenn DS, Steinhelper ME, Field LJ, Hill NS (1993) Cardiopulmonary responses to chronic hypoxia in transgenic mice that overexpress ANP. J Appl Physiol 75:198-205

25. He B, Xiao J, Ren AJ, Zhang YF, Zhang H, Chen M, Xie B, Gao XG, Wang YW (2011) Role of miR-1 and miR-133a in myocardial ischemic postconditioning. J Biomed Sci 18:22

26. Jeffery TK, Morrell NW (2002) Molecular and cellular basis of pulmonary vascular remodeling in pulmonary hypertension. Prog Cardiovasc Dis 45:173-202

27. Redout EM, Wagner MJ, Zuidwijk MJ, Boer C, Musters RJ, van Hardeveld C, Paulus WJ, Simonides WS (2007) Right-ventricular failure is associated with increased mitochondrial complex II activity and production of reactive oxygen species. Cardiovasc Res 75:770-781

28. Pullamsetti SS, Savai R, Janssen W, Dahal BK, Seeger W, Grimminger F, Ghofrani HA, Weissmann N, Schermuly RT
(2011) Inflammation, immunological reaction and role of infection in pulmonary hypertension. Clin Microbiol Infect 17:7-14

29. Li PC, Li SC, Lin YJ, Liang JT, Chien CT, Shaw CF (2005) Thoracic vagal efferent nerve stimulation evokes substance P-induced early airway bronchonstriction and late proinflammatory and oxidative injury in the rat respiratory tract. J Biomed Sci 12:671-681

30. Zhu Y, Zhang XL, Zhu BF, Ding YN (2012) Effect of antioxidant $\mathrm{N}$-acetylcysteine on diabetic retinopathy and expression of VEGF and ICAM-1 from retinal blood vessels of diabetic rats. Mol Biol Rep 39:3727-3735

31. Black SM, Fineman JR (2006) Oxidative and nitrosative stress in pediatric pulmonary hypertension: roles of endothelin-1 and nitric oxide. Vascul Pharmacol 45:308-316

32. Patel JD, Krupka T, Anderson JM (2007) iNOS-mediated generation of reactive oxygen and nitrogen species by biomaterialadherent neutrophils. J Biomed Mater Res A 80:381-390

33. Murad F (2004) Discovery of some of the biological effects of nitric oxide and its role in cell signaling. Biosci Rep 24:452-474

34. Winterbourn CC (2002) Biological reactivity and biomarkers of the neutrophil oxidant, hypochlorous acid. Toxicology 181-182:223-227 